\title{
TUBERCLES OF THE CHOROID
}

\author{
BY \\ R. S. ILLINGWORTH and J. LORBER \\ From the Department of Child Health, University of Sheffield
}

(RECEIVED FOR PUBLICATION JULY 5, 1956)

In 1948 two of us (Illingworth and Wright) reviewed the literature concerning tubercles of the choroid and described the natural history of the disease as seen in children under our care. We pointed out that the favourable response of children with miliary or meningeal tuberculosis to streptomycin treatment had for the first time made possible the study of the natural history of choroidal tubercles. Since that time we have had considerable further experience of miliary and meningeal tuberculosis and have been able to observe the choroidal tubercles in our original cases for several more years. Below is an account of our findings.

\section{Material}

Our original study was based on 60 cases of miliary and meningeal tuberculosis seen between January, 1947, and May, 1948. The total number of children with these conditions whom we have had under our care and personally examined between January, 1947 and January, 1956, is 224.

In recent years all the children have been heavily sedated with rectal thiopentone for ophthalmoscopic examination (Lorber, 1950).

\section{Incidence of Choroidal Tubercles}

We found choroidal tubercles in $86(38.4 \%)$ of the 224 cases of miliary and meningeal tuberculosis, including the original series. It is impossible to subdivide these cases accurately, because one cannot say with certainty that children with tuberculous meningitis have not also miliary tuberculosis. In our original paper we commented on the fact that the absence of radiological evidence of miliary tuberculosis by no means indicated that this would not be found at necropsy. Further study (Emery and Lorber, 1950), in which the radiological and pathological appearances were correlated, showed that the chief factor responsible for the characteristic radiological picture of miliary tuberculosis was the number and size of the tubercles. All one can do, therefore, is to divide cases into those with radiological or necropsy evidence of miliary tuberculosis, and those without. Table 1 shows that choroidal tubercles were found in 26 of 39 patients $(66.7 \%)$ with miliary tuberculosis who at the time of admission had no meningitis or subsequently developed it; in 44 of $60(73.3 \%)$ with tuberculous meningitis with radiological evidence of miliary spread; in five of 14 patients with tuberculous meningitis without radiological evidence but with the necropsy finding of miliary infection; and in 11 of 111 patients $(10.0 \%)$ with meningitis without clinical evidence of miliary tuberculosis, who survived, or in whom, if death occurred, no necropsy was performed. To put it in another way, we found choroidal tubercles in 16 out of 125 children $(12.8 \%)$ with tuberculous meningitis who had no radiological evidence of miliary tuberculosis, and in 70 out of 99 children $(70.7 \%)$ who had radiological evidence of miliary tuberculosis, with or without meningitis.

The Natural History of Choroidal Tubercles

One of us (J.L.) has followed up all survivors in

TABLE 1

THE INCIDENCE OF CHOROIDAL TUBERCLES

\begin{tabular}{|c|c|c|c|}
\hline & $\begin{array}{l}\text { Total } \\
\text { No. of } \\
\text { Children }\end{array}$ & $\begin{array}{l}\text { Number } \\
\text { Showing } \\
\text { Choroidal } \\
\text { Tubercles }\end{array}$ & $\begin{array}{l}\text { Percentage } \\
\text { Showing } \\
\text { Choroidal } \\
\text { Tubercles }\end{array}$ \\
\hline $\begin{array}{l}\text { Miliary tuberculosis without menin- } \\
\text { gitis on admission, or subse- } \\
\text { quently developing meningitis .. }\end{array}$ & 39 & 26 & $66 \cdot 7$ \\
\hline \multicolumn{4}{|l|}{$\begin{array}{l}\text { Tuberculous meningitis with radio- } \\
\text { logical evidence of miliary tuber- }\end{array}$} \\
\hline culosis $\quad \ldots \quad \ldots \quad \ldots$ & 60 & 44 & $73 \cdot 3$ \\
\hline $\begin{array}{l}\text { Meningitis without radiological } \\
\text { evidence but with necropsy find- } \\
\text { ing of miliary spread } .\end{array}$ & 14 & 5 & - \\
\hline \multicolumn{4}{|l|}{$\begin{array}{l}\text { Meningitis without clinical evi- } \\
\text { dence of miliary spread (no } \\
\text { necropsy in case of death) }\end{array}$} \\
\hline . $\quad \ldots$ & 224 & 86 & $38 \cdot 4$ \\
\hline \multirow{2}{*}{$\begin{array}{l}\text { Meningitis without radiological } \\
\text { evidence of miliary spread } \\
\text { Radiological evidence of miliary } \\
\text { tuberculosis with or without } \\
\text { meningitis } \\
\text {. . }\end{array}$} & 125 & 16 & $12 \cdot 8$ \\
\hline & 99 & 70 & $70 \cdot 6$ \\
\hline
\end{tabular}




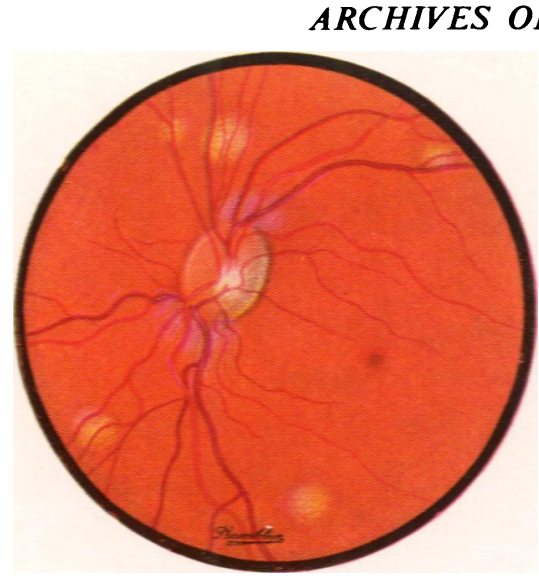

Fig. 1.-Earty stage.

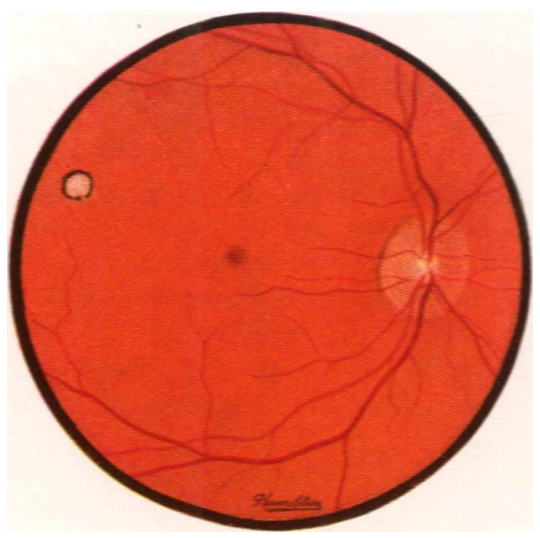

Fig. 3.-Late stage.

a special follow-up clinic and repeatedly examined their fundi. The longest period of observation of choroidal tubercles in a child was eight and a half years. During this period we did not observe the disappearance of any of the larger tubercles, but very small tubercles frequently disappeared. Before their final disappearance they became small, slit-like scars. Often these scars were so small that they could not be located unless each choroidal tubercle had been accurately mapped in its earlier stages.

McDermott, Muschenheim, Hadley, Bunn and Gorman (1947) noted the disappearance of these lesions in two out of 13 cases of miliary tuberculosis. Debré (1952) considered that small choroidal tubercles may disappear completely. It should be remembered that it is exceedingly easy to miss small choroidal tubercles, even on repeated examination. 
only, or with a mixture of early and later stages. Most early tubercles pass into this stage in four weeks or so, but some remain 'early' for several months. We now know that smaller choroidal tubercles remain in this second stage without apparent change over a course of years or they may disappear altogether. We were not aware of these facts when we wrote our original paper.

The larger choroidal tubercles undergo further notable changes in the next 12 or more weeks. The tubercle becomes paler still, eventually becoming parchment white with heavy black pigment around it and a clearly demarcated margin (Fig. 3). There may also be some paling of the red choroid immediately around the lesion. This corresponds to the third stage illustrated in the monograph by Monbrun and Lavat (1949-50). The last stage which we have seen, only after a period of three to four years after the first examination, is shown in Fig. 4. The parchment white area is now completely replaced by a mass of heavy black pigment. We have not seen a stage later than this, and we had not seen this stage when we wrote our original paper, neither have we ever seen an illustration of it.

\section{Choroidal Tubercles in Primary Tuberculosis}

In our previous communication we referred to four papers which mentioned the occurrence of choroidal tubercles without evidence of miliary tuberculosis, and described four patients ourselves who were found to have these lesions and survived without streptomycin and other specific therapy. One of them, however, showed fine miliary calcification in the lungs six years after the appearance of the choroidal tubercle. We have followed up these children for several years, and all have remained well. It has long been known that an occasional case of miliary tuberculosis recovers spontaneously without treatment, and one can never be sure from radiological studies that miliary spread has not occurred. Foissin (1949) reported a series of 15 cases in which choroidal tubercles were found in the absence of miliary or meningeal tuberculosis. Four were adolescents with primary tuberculosis. In two of them the tubercles healed during the period of observation, and in the other two they were healed when first seen. Eight cases had no other sign of tuberculosis, and were found in an eye clinic. Two were adults with healed tubercles. The other one was a girl of 6 years with severe primary tuberculosis of two years' duration who developed headache and vomiting but had a normal C.S.F. and no radiological evidence of miliary tuberculosis. She was found to have one healed choroidal tubercle, which was almost black, and two fresh choroidal tubercles which later healed. She subsequently developed a new choroidal tubercle. The findings suggested three separate haematogenous spreads.

Monbrun and Lavat (1949-50) found choroidal tubercles in six out of 100 cases of primary tuberculosis. They regarded their occurrence as evidence of an intense infection with a serious prognosis. Onfray (1953) described a single case in which he found a scotoma corresponding to a large solitary tubercle.

Since our original paper we have examined over 200 cases of apparently uncomplicated primary tuberculosis, mostly in children under 2 . In none of these did we find any choroidal tubercles. The examinations were done only at the time of the initial diagnosis, and subsequently if miliary spread was suspected because of suggestive symptoms. More frequent examinations might have disclosed an occasional choroidal tubercle.

\section{Summary and Conclusions}

The natural history and incidence of choroidal tubercles in 224 personally observed cases of miliary and meningeal tuberculosis were studied.

Choroidal tubercles were found in 16 of 125 children $(12 \cdot 8 \%)$ with tuberculous meningitis without radiological evidence of miliary spread, and in 70 of 99 children $(70.6 \%)$ with radiological evidence of miliary tuberculosis, with or without meningitis.

The natural history of the choroidal tubercle is described, including a description and illustration of a late stage which we have not seen described elsewhere.

We wish to thank the Tuberculosis Research Fund of the University of Sheffield for a grant for this study.

\section{REFERENCES}

Debré, R. (1952). Lancet, 2. 545.

Emery, J. L. and Lorber, J. (1950). Brit. med. J., 2, 702.

Foissin, J. (1949). Bull. Soc. Ophtal. Fr., p. 753.

Illingworth, R. S. and Wright, T. (1948). Brit. med. J., 2, 365 Lorber, J. (1950). Ibid., 2, 21.

Lorber, J. (195) Mudley, S. J., Bunn, P. A. and Gorman, R. V. (1947). Ann. intern. Med., 27. 769.

Monbrun, A. and Lavat, J. (1949-50). Ophtalmoscopie et Dissémination Tuberculeuse. Supplément au Bulletin des Sociètés dophtalmologie de France No. 3.

Onfray, M. (1953). Bull. Soc. Ophtal. Fr., p. 968. 